Article

\title{
Provincial Carbon Emissions Efficiency and Its Influencing Factors in China
}

\author{
Shi Wang ${ }^{1,2}$, Hua Wang ${ }^{3, *}$, Li Zhang ${ }^{4, *}$ and Jun Dang ${ }^{1,5}$ \\ 1 School of Economics and Finance, Xi'an International Studies University, Xi'an 710128, China; \\ wangshi1107@xisu.edu.cn (S.W.); dangjun@xisu.edu.cn (J.D.) \\ 2 "One Belt One Road" Economic and Trade Cooperation Innovation Team, Xi'an International Studies \\ University, Xi'an 710128, China \\ 3 School of Foreign Studies, Xi'an Jiaotong University, Xi'an 710049, China \\ 4 School of Journalism and New Media, Xi'an Jiaotong University, Xi'an 710049, China \\ 5 "One Belt One Road" Cross-Border Electronic Commerce Research Institute, Xi'an International Studies \\ University, Xi'an 710128, China \\ * Correspondence: seablue@mail.xjtu.edu.cn (H.W.); zhanglixinwen@mail.xjtu.edu.cn (L.Z.)
}

Received: 2 April 2019; Accepted: 18 April 2019; Published: 19 April 2019

\begin{abstract}
We calculated provincial carbon emissions efficiency and related influencing factors in China with the purpose of providing a reference for other developing countries to develop a green economy. Using panel data covering the period from 2004-2016 from 30 provinces in China, we calculated the carbon emission performance (CEP) and the technology gap ratio of carbon emission (TGR) with the data envelopment analysis (DEA) method and the meta-frontier model separately to analyze provincial carbon emissions efficiency in China. No matter which indicator was employed, we found that distinct differences exist in the eastern, the central, and the western regions of China, and the eastern region has the highest carbon emission performance, followed by the central and the western regions. Then, the panel data Tobit regression model was employed to analyze the influencing factors of carbon emissions efficiency, and we found that scale economy, industrial structure, degree of opening up, foreign direct investment (FDI), energy intensity, government interference, ownership structure, and capital-labor ratio have different impacts on the carbon emission efficiency in different regions of China, which indicates different policies should be implemented in different regions.
\end{abstract}

Keywords: carbon emissions efficiency; carbon emissions performance (CEP); technology gap ratio of carbon emissions (TGR); meta-frontier data envelopment analysis (DEA) model

\section{Introduction}

Carbon dioxide-based greenhouse gas emissions are posing a growing challenge to global climate change. The United Nation's (UN) intergovernmental Panel on Climate Change (IPCC) reported that the global average surface temperature rose by 0.6 degrees Celsius, and the snow cover area and the glacier area decreased by $10 \%$ and $10 \%-15 \%$, respectively, in the 20th century. The impact of human activities on greenhouse gas emissions continue to increase, and greenhouse gas will continue to be the key factor influencing the climate in the 21st century. Energy conservation and emission reduction has become a global consensus.

China has become the world's second largest greenhouse gas emitter-after the United States-since 2007. China is still in a period of rapid industrialization and urbanization, and its energy utilization technology and efficiency are generally lower than those of developed countries, resulting in high $\mathrm{CO}_{2}$ emissions. As a result, reducing $\mathrm{CO}_{2}$ emissions and improving carbon emission efficiency has become an important issue of long-term concern for China and the world. 
China has taken action. In the UN Climate Change Conference, which was held in Copenhagen in December 2009, Chinese representatives committed to lowering the per unit gross domestic product (GDP) carbon emissions in China by $40-45 \%$ by 2020 compared to the 2005 levels. China established its development goals towards 2020, which include voluntary reduction target, biological nitrogen fixation (BNF), and the usage of non-fossil fuels. In addition, in the outline of the 12th five-year plan for national economic and social development of the People's Republic of China, the carbon intensity reduction target of $17 \%$ has been clearly defined for the first time, that is, $17 \% \mathrm{CO}_{2}$ emission reduction at the same level of economic output. The 13th five-year plan further sets the goal of reducing China's carbon intensity by $18 \%$ by the end of 2020 compared with the end of 2015 . Due to the huge differences in economic scale, resource endowment, industrial structure, and energy consumption structure among Chinese provinces, the inter-provincial carbon intensity also varies greatly. It is extremely difficult for different regions to realize the goal of energy conservation and emissions reduction by adopting similar methods. Therefore, regions should put different emphasis on the carbon emissions reduction and the improvement of emission performance according to their own features. The study of carbon emission efficiency not only can give a clear understanding of the regional differences in carbon emission efficiency to improve policy-making's inharmonious development of regional economy, energy conservation, and emission reduction, but can also provide a reference for a low-cost, highly efficient, and regionally coordinated framework of energy conservation and emission reduction to achieve balanced regional development and the realization of national emission reduction goals.

The contributions of this paper are two-fold. First, we calculated the carbon emission performance (CEP) under both meta-frontier and group frontier with the data envelopment analysis (DEA) method and the meta-frontier model separately, then obtained the technology gap ratio of carbon emissions (TGR) to capture provincial carbon emissions efficiency in China, which is more reasonable than traditional methods such as single-factor carbon emission efficiency or Malmquist index because it allows comparison of the different carbon emission performances between different groups or regions in China. Second, the panel data Tobit model was adopted to analyze the influencing factors of CEP and TGR, and we studied the differences between the influencing factors of carbon emission efficiency in different regions within China, which provides a reference for other developing countries to develop green economy. The remainder of the paper is structured as follows. Section 2 presents literature review. Sections 3 and 4 present the calculation of Chinese provincial carbon emission efficiency under the DEA method and the meta-frontier model separately. Section 5 contains analysis of factors influencing carbon emissions efficiency. Section 6 presents conclusions and discussion, and Section 7 presents policy suggestions.

\section{Literature Review}

\subsection{The Measurement of Carbon Emission}

The measurement of carbon emission mainly includes two methods-model-estimating and material measurement. The model-estimating method is to conduct scenario analysis and policy stimulation of carbon emissions by establishing relevant mathematical models, which mainly include the MARKAL energy system model, the input-output model, the system dynamics model, the logistic model, the life-cycle model, and so on. These models are commonly used for calculation of carbon emissions at a national level.

The input-output analysis (IOA) method and the life-cycle approach (LCA) are common methods in economics, which were firstly put forward by Herendeen [1]. The thing to note is that LCA is often confined to one industry. Based on the LCA method, Kok et al. [2] divided the carbon emission measurement into three kinds-the basic input-output energy analysis method, the hybrid energy analysis method, and the input-output plus household expenditure method, among which the basic input-output (IO) analysis method is the most widely used [3]. Cho and Chae [4] estimated the carbon emissions and their reduction from construction materials (especially concrete) between conventional 
products and low-carbon materials in South Korea by using the LCA method. Zhang et al. [5] and Li et al. [6] used an IO model to analyze embodied energy flows and factors causing energy consumption growth in China to develop a sustainable energy conservation policy. Wang et al. [7] employed IO analysis to investigate the embodied energy in the sub-process order of supply chains. Supasa et al. [8] applied an energy IO model using data for Thailand in 2000 and 2010, which permitted the identification of the nation's embodied energy and $\mathrm{CO}_{2}$ inventory and an analysis of structural changes over a 10 -year period. Using China's interregional IO tables and the corresponding carbon emission data for 2007 and 2010, Xie et al. [9] proposed an interregional Ghosh IO model and estimated the amount of interprovincial carbon emission transfer from the supply-side perspective. Ju and Fujikawa [10] adopted an IO-based model to quantify the production-based and the consumption-based emission flows in all regions of China, as well as to estimate the increase of household consumption in all sectors.

The material measurement method is commonly used in the measurement of carbon emissions at regional and industrial levels. This method was employed by Schimel [11] to measure the carbon emissions in some major countries in the 1980s, a study that concluded that $78 \%$ of the global carbon emissions are caused by the burning of fossil fuels and cement production. In addition to the above-mentioned methods, there are also many other methods for the measurement of carbon emissions, such as factor-decomposition analysis, the Kaya Model, and the method of carbon footprint, which have been used by recent researchers such as Kasperowicz [12], Zimmermannová et al. [13], Stavytskyy et al. [14], and Straczewska [15].

\subsection{Related Research on Carbon Emission Efficiency}

Single-factor indictor is the earliest indicator of carbon emission performance, and the ratio between the carbon emissions and a certain element is usually regarded as the standard of carbon emission efficiency, which includes the carbon production efficiency proposed by Japanese scholar Kaya, the consumption of carbon dioxide per unit energy proposed by Mielnik and Goldemberg, and the carbon intensity proposed by Sun [16]. Currently, the frequently-used method is the DEA method proposed by Charnes and Cooper [17]. The DEA method is an efficiency appraisal method developed from the concept of relative efficiency. It can deal with the multi-input, multi-output model and measure comprehensive environment performance index or total-factor Malmquist index. Based on the framework of total-factor productivity, Hu and Wang [18] firstly put forward the concept of total-factor energy efficiency using the DEA method, Forsund and Kittelsen [19] defined the concept of total-factor energy efficiency based on the Malmquist index, and many academics have developed this method. Wang et al. [20] used the stochastic frontier analysis (SFA) method of energy efficiency, incorporating energy structure, economic structure, human capital, capital stock, and potential energy efficiency to identify an efficient pathway for achieving emissions reduction targets.

The meta-frontier concept was firstly put forward by Hayami [21]. Battese and Rao [22] and some other researchers [23] proposed the two key efficiency indicators of technical efficiency and technology gap ratio by adopting the concept of meta-production function. O'Donnell et al. [23] applied the meta-frontier model into the real efficiency measurement. In this paper, we go further and use the TGR index to take technical gaps into account.

\subsection{Related Research on Influencing Factors of Carbon Emission}

The index decomposition method decomposes the changes of the object variables into the changes of several influencing factors and then evaluates the contributions of every influencing factor on the changes of object variables. The Divisia decomposition method and the Lespeyres decomposition method are the most widely used methods, however, most scholars consider the logarithmic mean divisia index (LMDI) as the best method. From the perspective of supply and demand, Wu et al. [24] decomposed factors that influenced the carbon emissions from 1980 to 2002 in China by adopting the LMDI method.

The Environment Kuznets Curve (EKC) is an important tool in the analysis of the relationship between economic quality and environmental quality. Research by Galeottia and Lanza [25] proved 
that the EKC exists in many developed countries, but there are no clear traces to prove its existence in developing countries.

Chang and Lahr [26] indicated that between 2005 and 2010, improving emission intensity and input intensity helped to reduce $\mathrm{CO}_{2}$ emissions; meanwhile, capital investment explained the majority of the increases in $\mathrm{CO}_{2}$ emissions brought about by final demand, and import substitution was also observed to increase $\mathrm{CO}_{2}$ emissions. Su et al. [26] analyzed Singapore's carbon emissions from the demand perspective using the IO method and investigated the drivers of emission changes using structural decomposition analysis (SDA). The results show that exports accounted for nearly two-thirds of its total emissions, and growth in emissions in the last decade was largely export-driven. Emissions increased as export-oriented industries and export volume expanded. Fuel switching and energy efficiency helped to lower growth in emissions. Morioka et al. [27] described an SDA of Japanese greenhouse gas (GHG) emissions from 1990 to 2005 and found that forward linkage and kernel structure contributed to a rise in GHG emissions, and that backward linkage consistently increased emissions in the three periods. Other recent studies include Hu et al. [28], Wang et al. [29], Zhang et al. [30], and Shao et al. [31].

\section{Evaluation of Chinese Provincial Carbon Emission Efficiency}

\subsection{Measurement of Chinese Provincial Carbon Emission}

Based upon the data availability and comparison between various accounting methods, this article chose the calculating method recommended by the IPCC (International Panel on Climate Change) in IPCC National Guidelines for Greenhouse Gasesin 2006 and converted the energy data in China into caloric value. In this article, eight kinds of energy consumption data in the China Energy Statistical Yearbook were adopted and multiplied by the corresponding average low heating values and default carbon emission factors to get the carbon emissions of energy consumption in each province during the period from 2004 to 2016.

\subsection{Single-Factor Carbon Emission Efficiency}

\subsubsection{Per Capita Carbon Emission}

Per capita carbon emission: the average carbon emissions produced by each person in a region each year; the formula is:

$$
Q_{m}=C_{m} / P_{m}
$$

In this formula, $P_{\mathrm{m}}$ refers to the year-end total population, which is used to measure the carbon emissions on an individual basis and represents that, in the social development of human beings, everyone has equal rights to survival, development, and the utilization of natural resources.

Substituting the 2004-2016 carbon emissions in each province and the year-end total population into the above formula, we obtain the per capita carbon emissions in each province in each year, as shown in Table 1.

Table 1. Per capita carbon emissions in provinces of China (2004-2016) t/per capita.

\begin{tabular}{cccccccccccccc}
\hline District & $\mathbf{2 0 0 4}$ & $\mathbf{2 0 0 5}$ & $\mathbf{2 0 0 6}$ & $\mathbf{2 0 0 7}$ & $\mathbf{2 0 0 8}$ & $\mathbf{2 0 0 9}$ & $\mathbf{2 0 1 0}$ & $\mathbf{2 0 1 1}$ & $\mathbf{2 0 1 2}$ & $\mathbf{2 0 1 3}$ & $\mathbf{2 0 1 4}$ & $\mathbf{2 0 1 5}$ & $\mathbf{2 0 1 6}$ \\
\hline Beijing & 2.08 & 1.98 & 2.02 & 2.19 & 2.16 & 2.11 & 2.12 & 1.99 & 1.92 & 1.83 & 1.65 & 1.58 & 1.54 \\
Tianjin & 2.59 & 2.69 & 2.94 & 3.29 & 3.45 & 3.56 & 3.64 & 3.43 & 3.53 & 4.04 & 4.25 & 4.09 & 4.11 \\
Hebei & 1.39 & 1.53 & 1.74 & 2.01 & 2.50 & 2.67 & 2.90 & 2.99 & 3.17 & 3.33 & 3.74 & 3.76 & 3.81 \\
Shanxi & 3.23 & 3.92 & 4.40 & 4.63 & 5.08 & 5.61 & 5.81 & 5.55 & 5.46 & 5.60 & 6.14 & 6.37 & 6.40 \\
Inner Monglia & 1.74 & 1.92 & 2.50 & 3.15 & 3.89 & 6.20 & 5.18 & 6.12 & 6.60 & 7.25 & 9.06 & 9.40 & 9.41 \\
Liaoning & 2.41 & 2.49 & 2.71 & 2.99 & 3.36 & 3.59 & 3.84 & 3.99 & 4.11 & 4.47 & 4.74 & 4.87 & 4.89 \\
Jilin & 1.30 & 1.35 & 1.53 & 1.63 & 1.89 & 1.99 & 2.10 & 2.36 & 2.41 & 2.67 & 3.07 & 3.03 & 3.04 \\
Heilongjiang & 1.39 & 1.38 & 1.54 & 1.68 & 1.89 & 2.01 & 2.16 & 2.30 & 2.40 & 2.60 & 2.79 & 2.93 & 3.01 \\
Shanghai & 3.11 & 3.17 & 3.36 & 3.38 & 3.47 & 3.31 & 3.23 & 3.28 & 3.15 & 3.29 & 3.30 & 3.18 & 3.20 \\
Jiangsu & 0.99 & 1.06 & 1.19 & 1.45 & 1.87 & 2.01 & 2.15 & 2.16 & 2.24 & 2.48 & 2.84 & 2.88 & 2.91 \\
Zhejiang & 1.05 & 1.20 & 1.33 & 1.53 & 1.76 & 1.95 & 2.14 & 2.16 & 2.22 & 2.29 & 2.41 & 2.33 & 2.35 \\
\hline
\end{tabular}


Table 1. Cont.

\begin{tabular}{cccccccccccccc}
\hline District & $\mathbf{2 0 0 4}$ & $\mathbf{2 0 0 5}$ & $\mathbf{2 0 0 6}$ & $\mathbf{2 0 0 7}$ & $\mathbf{2 0 0 8}$ & $\mathbf{2 0 0 9}$ & $\mathbf{2 0 1 0}$ & $\mathbf{2 0 1 1}$ & $\mathbf{2 0 1 2}$ & $\mathbf{2 0 1 3}$ & $\mathbf{2 0 1 4}$ & $\mathbf{2 0 1 5}$ & $\mathbf{2 0 1 6}$ \\
\hline Anhui & 0.75 & 0.78 & 0.87 & 0.89 & 0.96 & 1.03 & 1.15 & 1.31 & 1.44 & 1.57 & 1.69 & 1.74 & 1.77 \\
Fujian & 0.57 & 0.67 & 0.79 & 0.90 & 1.10 & 1.21 & 1.36 & 1.41 & 1.64 & 1.77 & 2.00 & 1.97 & 2.01 \\
Jiangxi & 0.50 & 0.52 & 0.61 & 0.74 & 0.81 & 0.87 & 0.95 & 0.96 & 0.99 & 1.15 & 1.26 & 1.25 & 1.22 \\
Shandong & 0.99 & 1.08 & 1.31 & 1.66 & 2.28 & 2.59 & 2.80 & 2.95 & 3.05 & 3.32 & 3.48 & 3.63 & 3.71 \\
Henan & 0.69 & 0.75 & 0.76 & 1.07 & 1.34 & 1.52 & 1.69 & 1.73 & 1.75 & 1.91 & 2.11 & 1.95 & 2.01 \\
Hubei & 0.86 & 0.92 & 1.02 & 1.13 & 1.25 & 1.40 & 1.55 & 1.51 & 1.62 & 1.86 & 2.10 & 2.09 & 2.11 \\
Hunan & 0.49 & 0.52 & 0.59 & 0.72 & 1.01 & 1.08 & 1.24 & 1.22 & 1.28 & 1.32 & 1.47 & 1.43 & 1.41 \\
Guangdong & 0.83 & 0.88 & 0.98 & 1.10 & 1.22 & 1.31 & 1.38 & 1.39 & 1.44 & 1.58 & 1.69 & 1.65 & 1.72 \\
Guangxi & 0.35 & 0.36 & 0.42 & 0.55 & 0.63 & 0.68 & 0.78 & 0.79 & 0.87 & 1.11 & 1.34 & 1.46 & 1.33 \\
Hainan & 0.41 & 0.17 & 0.60 & 0.49 & 0.43 & 0.68 & 1.35 & 1.38 & 1.47 & 1.58 & 1.77 & 1.85 & 1.79 \\
Chongqing & 0.65 & 0.74 & 0.89 & 0.98 & 1.07 & 1.16 & 1.26 & 1.30 & 1.39 & 1.52 & 1.72 & 1.66 & 1.77 \\
Sichuan & 0.43 & 0.50 & 0.64 & 0.74 & 0.77 & 0.85 & 0.96 & 1.02 & 1.13 & 1.15 & 1.18 & 1.23 & 1.28 \\
Guizhou & 0.83 & 0.87 & 1.10 & 1.28 & 1.33 & 1.55 & 1.70 & 1.75 & 1.96 & 2.00 & 2.34 & 2.42 & 2.33 \\
Yunnan & 0.54 & 0.65 & 0.82 & 1.01 & 1.18 & 1.29 & 1.34 & 1.37 & 1.48 & 1.55 & 1.59 & 1.64 & 1.71 \\
Shaanxi & 0.74 & 0.84 & 0.95 & 1.18 & 1.41 & 1.71 & 1.85 & 2.04 & 2.21 & 2.62 & 2.90 & 3.34 & 3.21 \\
Gansu & 1.02 & 1.07 & 1.20 & 1.35 & 1.47 & 1.56 & 1.74 & 1.77 & 1.75 & 1.95 & 2.25 & 2.30 & 2.29 \\
Qinghai & 0.91 & 0.88 & 0.97 & 1.01 & 1.36 & 1.57 & 1.85 & 1.94 & 1.95 & 1.93 & 2.22 & 2.61 & 2.57 \\
Ningxia & 3.55 & 0.52 & 3.51 & 3.18 & 3.64 & 3.93 & 4.33 & 4.75 & 5.17 & 6.03 & 7.99 & 8.44 & 8.32 \\
Xinjiang & 1.51 & 1.56 & 1.66 & 1.85 & 2.07 & 2.31 & 2.47 & 2.71 & 3.18 & 3.50 & 4.10 & 4.73 & 4.68 \\
Nationwide & 1.01 & 1.08 & 1.24 & 1.43 & 1.66 & 1.85 & 1.98 & 2.05 & 2.16 & 2.35 & 2.60 & 2.65 & 2.71 \\
\hline
\end{tabular}

According to Table 1, the per capita carbon emissions (2004-2016) in each province had a clear increasing tendency by year. The main reason is that, in each province (except for Beijing), the population grew much slower than the growth rate of carbon emissions. The average carbon emission in China is 2.71 tons per person, but provinces have great differences in per capita carbon emissions.

\subsubsection{Carbon Intensity}

Carbon intensity refers to the carbon emissions for one-unit output in a region; the formula is:

$$
I_{m}=C_{m} / G_{m}
$$

In this formula, $C_{\mathrm{m}}$ refers to the calculated carbon emissions in region $\mathrm{m}$, and $G_{\mathrm{m}}$ refers to the GDP of this region. To remove the impact of inflation, $G_{m}$ equals the real GDP in 2004, the base period. The real GDP = nominal GDP/GDP deflator (fixed base). As an indicator reflecting regional energy utilization efficiency, a lower number of carbon intensity shows higher regional energy utilization efficiency and higher carbon emission efficiency. Substituting the carbon emissions (2004-2016) in each province and the real GDP into the above formula, we get the carbon intensity of every province, as shown in Table 2.

Table 2. Intensity in provinces of China t/10,000 Yuan RMB.

\begin{tabular}{cccccccccccccc}
\hline District & $\mathbf{2 0 0 4}$ & $\mathbf{2 0 0 5}$ & $\mathbf{2 0 0 6}$ & $\mathbf{2 0 0 7}$ & $\mathbf{2 0 0 8}$ & $\mathbf{2 0 0 9}$ & $\mathbf{2 0 1 0}$ & $\mathbf{2 0 1 1}$ & $\mathbf{2 0 1 2}$ & $\mathbf{2 0 1 3}$ & $\mathbf{2 0 1 4}$ & $\mathbf{2 0 1 5}$ & $\mathbf{2 0 1 6}$ \\
\hline Beijing & 1.07 & 0.94 & 0.88 & 0.86 & 0.78 & 0.70 & 0.65 & 0.59 & 0.54 & 0.49 & 0.42 & 0.39 & 0.38 \\
Tianjin & 1.45 & 1.34 & 1.28 & 1.25 & 1.16 & 1.08 & 0.99 & 0.84 & 0.78 & 0.80 & 0.76 & 0.67 & 0.65 \\
Hebei & 1.71 & 1.73 & 1.77 & 1.82 & 2.01 & 1.91 & 1.85 & 1.74 & 1.69 & 1.62 & 1.64 & 1.52 & 1.50 \\
Shanxi & 5.90 & 6.39 & 6.29 & 5.78 & 5.67 & 5.58 & 5.01 & 4.44 & 4.16 & 3.90 & 3.81 & 3.61 & 3.55 \\
Inner Monglia & 2.70 & 2.63 & 2.91 & 3.05 & 3.05 & 4.10 & 2.89 & 2.92 & 2.71 & 2.60 & 2.86 & 2.67 & 2.66 \\
Liaoning & 2.04 & 1.92 & 1.87 & 1.83 & 1.84 & 1.74 & 1.63 & 1.50 & 1.37 & 1.32 & 1.25 & 1.17 & 1.02 \\
Jilin & 1.77 & 1.68 & 1.73 & 1.65 & 1.71 & 1.57 & 1.42 & 1.39 & 1.25 & 1.22 & 1.23 & 1.08 & 1.05 \\
Heilongjiang & 1.54 & 1.39 & 1.41 & 1.38 & 1.39 & 1.32 & 1.27 & 1.21 & 1.13 & 1.09 & 1.04 & 0.99 & 0.97 \\
Shanghai & 1.05 & 0.99 & 0.96 & 0.88 & 0.84 & 0.74 & 0.65 & 0.63 & 0.58 & 0.57 & 0.54 & 0.49 & 0.48 \\
Jiangsu & 0.77 & 0.75 & 0.75 & 0.80 & 0.91 & 0.86 & 0.80 & 0.72 & 0.67 & 0.66 & 0.69 & 0.63 & 0.60 \\
Zhejiang & 0.76 & 0.77 & 0.76 & 0.77 & 0.80 & 0.79 & 0.77 & 0.71 & 0.68 & 0.65 & 0.63 & 0.56 & 0.52 \\
Anhui & 1.34 & 1.28 & 1.30 & 1.20 & 1.13 & 1.08 & 1.05 & 1.07 & 1.04 & 0.96 & 0.91 & 0.84 & 0.77 \\
Fujian & 0.46 & 0.50 & 0.53 & 0.55 & 0.60 & 0.58 & 0.57 & 0.53 & 0.55 & 0.53 & 0.54 & 0.48 & 0.46 \\
Jiangxi & 0.97 & 0.91 & 0.95 & 1.03 & 1.00 & 0.97 & 0.94 & 0.84 & 0.78 & 0.79 & 0.78 & 0.70 & 0.68 \\
Shandong & 0.97 & 0.94 & 1.02 & 1.12 & 1.34 & 1.34 & 1.28 & 1.21 & 1.12 & 1.10 & 1.04 & 1.00 & 0.98 \\
\hline
\end{tabular}


Table 2. Cont.

\begin{tabular}{cccccccccccccc}
\hline District & $\mathbf{2 0 0 4}$ & $\mathbf{2 0 0 5}$ & $\mathbf{2 0 0 6}$ & $\mathbf{2 0 0 7}$ & $\mathbf{2 0 0 8}$ & $\mathbf{2 0 0 9}$ & $\mathbf{2 0 1 0}$ & $\mathbf{2 0 1 1}$ & $\mathbf{2 0 1 2}$ & $\mathbf{2 0 1 3}$ & $\mathbf{2 0 1 4}$ & $\mathbf{2 0 1 5}$ & $\mathbf{2 0 1 6}$ \\
\hline Henan & 1.21 & 1.20 & 1.12 & 1.38 & 1.47 & 1.45 & 1.40 & 1.29 & 1.19 & 1.14 & 1.12 & 0.94 & 0.91 \\
Hubei & 1.06 & 1.04 & 1.06 & 1.05 & 1.04 & 1.03 & 0.99 & 0.85 & 0.81 & 0.81 & 0.81 & 0.73 & 0.71 \\
Hunan & 0.82 & 0.81 & 0.84 & 0.92 & 1.09 & 1.02 & 1.03 & 0.89 & 0.82 & 0.76 & 0.75 & 0.66 & 0.61 \\
Guangdong & 0.70 & 0.67 & 0.66 & 0.65 & 0.64 & 0.62 & 0.58 & 0.54 & 0.52 & 0.53 & 0.52 & 0.47 & 0.42 \\
Guangxi & 0.73 & 0.68 & 0.74 & 0.87 & 0.84 & 0.81 & 0.81 & 0.73 & 0.72 & 0.76 & 0.83 & 0.81 & 0.80 \\
Hainan & 0.58 & 0.23 & 0.72 & 0.54 & 0.43 & 0.61 & 1.06 & 0.98 & 0.95 & 0.89 & 0.89 & 0.86 & 0.85 \\
Chongqing & 1.04 & 1.08 & 1.16 & 1.14 & 1.12 & 1.08 & 1.01 & 0.92 & 0.87 & 0.81 & 0.80 & 0.68 & 0.61 \\
Sichuan & 0.80 & 0.84 & 0.97 & 0.99 & 0.92 & 0.89 & 0.88 & 0.83 & 0.82 & 0.71 & 0.63 & 0.59 & 0.55 \\
Guizhou & 2.93 & 2.83 & 3.30 & 3.47 & 3.09 & 3.14 & 2.96 & 2.72 & 2.68 & 2.39 & 2.43 & 2.22 & 2.14 \\
Yunnan & 1.10 & 1.21 & 1.42 & 1.60 & 1.72 & 1.70 & 1.58 & 1.47 & 1.43 & 1.34 & 1.22 & 1.12 & 1.07 \\
Shaanxi & 1.52 & 1.55 & 1.58 & 1.74 & 1.85 & 1.98 & 1.85 & 1.75 & 1.68 & 1.74 & 1.70 & 1.74 & 1.73 \\
Gansu & 2.32 & 2.23 & 2.25 & 2.28 & 2.22 & 2.11 & 2.10 & 1.95 & 1.74 & 1.74 & 1.78 & 1.63 & 1.57 \\
Qinghai & 1.65 & 1.43 & 1.42 & 1.33 & 1.61 & 1.66 & 1.73 & 1.61 & 1.48 & 1.28 & 1.31 & 1.38 & 1.32 \\
Ningxia & 6.85 & 5.90 & 5.56 & 4.60 & 4.75 & 4.60 & 4.55 & 4.51 & 4.38 & 4.56 & 5.44 & 5.22 & 5.14 \\
Xinjiang & 2.08 & 1.95 & 1.90 & 1.93 & 1.99 & 2.03 & 1.99 & 2.06 & 2.21 & 2.23 & 2.36 & 2.45 & 2.44 \\
Nationwide & 1.22 & 1.18 & 1.22 & 1.25 & 1.29 & 1.27 & 1.19 & 1.11 & 1.05 & 1.01 & 1.01 & 0.93 & 0.88 \\
\hline
\end{tabular}

In Table 2, the carbon emissions in all provinces of the eastern and central regions of China showed the tendency of decreasing every year. In some provinces in the eastern region, such as Beijing, Shanghai, Guangdong, Fujian, etc., the carbon intensity was below 0.5 tons/10,000 RMB by 2016. The five provinces (Chongqing, Sichuan, Guizhou, Yunnan, and Shaanxi) in western regions had a tendency of descending after ascending. Provinces such as Ningxia, Xinjiang, and Inner Mongolia showed a state of irregular fluctuation during the 13 years. The carbon intensity of Ningxia province exceeded that of Shanxi province in 2011 and became the highest one.

\subsection{Total-Factor Carbon Emission Efficiency}

Carbon emissions are influenced by resource endowment, mode and level of economic development, and economic structure. Single-factor carbon emission efficiency focuses on their relation with GDP, and it cannot comprehensively measure the complex relation between carbon emissions and the various aspects of economic entities. Therefore, the DEA model was introduced to calculate the total-factor carbon emission efficiency, i.e., the CEP, which includes many variables.

\section{(1) DEA method}

The DEA is an important nonparametric method to evaluate productivity. The advantage of the DEA method is that it is based on the concept of relative efficiency, uses mathematical programming model to determine the production frontier, calculates and compares the degree of deviation of a decision-making unit (DMU) from the frontier to measure its efficiency, and can fully consider the optimal IO scheme for DMU itself when evaluating objects. In addition, when THE DEA method is used to build the model, the optimal efficiency index of the DMU is irrelevant with the dimensionless original value of the IO index, thus no relevant processing is required.

There are also disadvantages of the DEA model. On the one hand, it can distinguish whether a DMU is effective or not, that is, which DMU is at the efficiency frontier with the efficiency value of one and which DMU is inefficient with the efficiency value less than one; however, in the actual measurement, many DMU efficiency values are all one, thus it is impossible to compare the efficiency of an effective DMU and further analyze the effective DMU. On the other hand, O'Donnell et al. [23] proposed the output-distant function defined meta-frontier model in which, if $\mathrm{X}$ and $\mathrm{Y}$ represent the non-negative input vector and the output vector, then different DMUs will generate different IO sets with different production technologies. The set is expressed as: $C E P=[(X, Y): X \geq 0 ; Y \geq 0$; $\mathrm{X}$ can generate $\mathrm{Y}]$. The frontier formed by this output set is called the meta-frontier. Because the hypothesis of technological homogeneity is not completely valid, the technology efficiency value under the meta-frontier, i.e., CEP calculated by the DEA model, will have some deviations. 
Therefore, all these DMUs must be divided into different groups. Then, the DEA method must be used to obtain group frontiers in different groups. However, the technical efficiency value under the group frontier is inaccurate as well, because it will be over-estimated for merely consulting technical levels within groups and neglecting the overall technical level. The ratio between them is the TGR of carbon emissions that shows technical differences between groups and the meta-frontier. This indicator overcomes the above shortcomings and makes an accurate comparison of carbon emission technology among different technical groups.

As the result, we mainly used the TGR to capture provincial carbon emissions efficiency in China, which is more reasonable than traditional methods such as single-factor carbon emission efficiency and the Malmquist index because it allows comparison of differences in carbon emission performance between different groups or regions in China. However, CEP under the meta-frontier calculated by the DEA model should be calculated first, because it is a basis of the calculation of TGR.

The basic model of the DEA method includes the CCR (Charnes \& Cooper \& Rhodes) model and the BCC (Banker \& Charnes \& Cooper) model. The CCR model is based on constant returns to scale and is used to evaluate comprehensive efficiency, while the BCC model is based on variable returns to scale and is used to evaluate technical efficiency. Charnes [17] successfully solved the problem in calculation and technique by introducing the non-Archimedean infinitely small quantity (generally, $\varepsilon=10^{-7}$ in practical use) in 1981, and by adding the slack variables $s^{-}$and $s^{+}$, established the CCR model and the BCC model with the non-Archimedean infinitely small quantity $\varepsilon$,. The two models are as follows:

$$
\begin{gathered}
\min \left[\theta-\varepsilon\left(\hat{\mathrm{e}}^{\mathrm{T}} \mathrm{s}^{-}+e^{T} s^{+}\right)\right]=\mathrm{v}_{\mathrm{D} 1} \\
\left\{\begin{array}{c}
\sum_{j=1}^{\mathrm{n}} X_{j} \lambda_{j}+s^{-}=\theta \mathrm{X}_{0} \\
\sum_{j=1}^{\mathrm{n}} Y_{j} \lambda_{j}-s^{+}=Y_{0} \\
\lambda_{\mathrm{j}} \geq 0, j=1,2, \cdots, n, s^{+} \geq 0, s^{-} \geq 0 \\
\hat{\mathrm{e}}^{\mathrm{T}}=(1,1, \cdots, 1) \in \mathrm{E}_{\mathrm{m}} e^{T}=(1,1, \cdots, 1) \in \mathrm{E}_{\mathrm{S}}
\end{array}\right. \\
\quad \min \left[\theta-\varepsilon\left(\hat{\mathrm{e}}^{\mathrm{T}} \mathrm{s}^{-}+e^{T} \mathrm{~s}^{+}\right)\right]=\mathrm{V}_{\mathrm{D} 2} \\
\quad \mathrm{~S} . \mathrm{t} \\
\left\{\begin{array}{l}
\mathrm{n} X_{j} \lambda_{j}+s^{-}=\theta X_{0} \\
j=1 \\
\sum_{j=1}^{n} Y_{j} \lambda_{j}-s^{+}=Y_{0} \\
\sum_{j=1}^{n} \lambda_{j}=1 \\
\lambda_{j} \geq 0, j=1,2, \cdots, n, s^{+} \geq 0, s^{-} \geq 0 \\
\hat{\mathrm{e}}^{T}=(1,1, \cdots, 1) \in \mathrm{E}_{\mathrm{m}} \mathrm{e}^{T}=(1,1, \cdots, 1) \in \mathrm{E}_{s}
\end{array}\right.
\end{gathered}
$$

$\theta$ represents the efficiency value of a DMU and has the property of $0 \leq \theta \leq 1, \lambda_{j}$ refers to the reconstructed portfolio ratio of the $j$ th in an effective DMU combination. For the optimum solution of the above model, when $\theta=1$ and $s^{-}=s^{+}=0$ in a DMU, the DMU is valid.

\section{(2) Data resources and indicators description}

This article conducted the measurement of carbon emission performance by choosing capital stock, labor force, and energy consumption as input elements, and the real GDP and carbon emissions as output elements in 30 provinces of China during 13 years (2004-2016). The measurement of capital stock was based on the perpetual inventory method, and the formula is: $K_{i t}=K_{i t-1}\left(1-\delta_{i t}\right)+I_{i t}$. The measurement of carbon emission performance used the traditional DEA model, which needed 
some transformation of the undesirable outputs carbon emissions. This article referred to the linear data conversion function proposed by Seiford and Zhu [32] to deal with the transformation. The data came from China Energy Statistic Yearbook and the IPCC National Guidelines for Greenhouse Gases.

\section{(3) The measurement of CEP}

According to the annual IO cross-sectional data in each province, the CEP in 30 provinces of China during the 13 years (2004-2016) could be obtained by selecting the IO DEA-BCC model and using DEAP 2.1 software. The results are shown in Table 3.

Table 3. Carbon emission performance in provinces of China (2004-2016).

\begin{tabular}{|c|c|c|c|c|c|c|c|c|c|c|c|c|c|}
\hline District & 2004 & 2005 & 2006 & 2007 & 2008 & 2009 & 2010 & 2011 & 2012 & 2013 & 2014 & 2015 & 2016 \\
\hline Beijing & 0.81 & 0.77 & 0.77 & 0.76 & 0.79 & 0.82 & 0.82 & 0.85 & 0.85 & 0.86 & 0.89 & 0.88 & 0.87 \\
\hline Tianjin & 0.98 & 1.00 & 1.00 & 1.00 & 1.00 & 0.95 & 1.00 & 1.00 & 1.00 & 1.00 & 1.00 & 1.00 & 1.00 \\
\hline Hebei & 0.73 & 0.71 & 0.72 & 0.74 & 0.76 & 0.78 & 0.76 & 0.74 & 0.71 & 0.74 & 0.73 & 0.72 & 0.73 \\
\hline Shanxi & 0.68 & 0.66 & 0.69 & 0.72 & 0.73 & 0.74 & 0.72 & 0.68 & 0.64 & 0.63 & 0.61 & 0.62 & 0.61 \\
\hline Inner Monglia & 0.85 & 0.85 & 0.92 & 0.94 & 0.95 & 0.86 & 0.84 & 0.80 & 0.77 & 0.73 & 0.71 & 0.66 & 0.68 \\
\hline Liaoning & 0.96 & 1.00 & 1.00 & 1.00 & 1.00 & 1.00 & 0.98 & 0.96 & 0.89 & 0.90 & 0.88 & 0.80 & 0.88 \\
\hline Jilin & 0.85 & 0.86 & 0.88 & 0.89 & 0.91 & 0.88 & 0.86 & 0.80 & 0.74 & 0.70 & 0.68 & 0.67 & 0.65 \\
\hline Heilongjiang & 0.85 & 0.90 & 0.93 & 0.96 & 1.00 & 1.00 & 1.00 & 1.00 & 1.00 & 1.00 & 1.00 & 1.00 & 1.00 \\
\hline Shanghai & 1.00 & 1.00 & 1.00 & 1.00 & 1.00 & 1.00 & 1.00 & 1.00 & 1.00 & 1.00 & 1.00 & 1.00 & 1.00 \\
\hline Jiangsu & 0.95 & 1.00 & 1.00 & 0.98 & 0.93 & 0.94 & 0.94 & 0.96 & 0.96 & 0.97 & 0.96 & 0.93 & 0.96 \\
\hline Zhejiang & 0.92 & 0.91 & 0.90 & 0.89 & 0.91 & 0.94 & 0.90 & 0.90 & 0.91 & 0.91 & 0.91 & 0.92 & 0.92 \\
\hline Anhui & 0.83 & 0.85 & 0.87 & 0.92 & 0.96 & 0.97 & 0.99 & 0.99 & 0.99 & 1.00 & 1.00 & 0.92 & 0.91 \\
\hline Fujian & 1.00 & 1.00 & 1.00 & 1.00 & 1.00 & 1.00 & 1.00 & 1.00 & 1.00 & 1.00 & 1.00 & 1.00 & 1.00 \\
\hline Jiangxi & 0.99 & 0.95 & 1.00 & 1.00 & 1.00 & 0.98 & 0.95 & 0.95 & 0.95 & 0.93 & 0.93 & 0.86 & 0.90 \\
\hline Shandong & 0.88 & 0.82 & 0.83 & 0.84 & 0.86 & 0.85 & 0.87 & 0.87 & 0.88 & 0.87 & 0.84 & 0.82 & 0.83 \\
\hline Henan & 0.81 & 0.80 & 0.77 & 0.81 & 0.84 & 0.84 & 0.83 & 0.80 & 0.77 & 0.73 & 0.71 & 0.70 & 0.72 \\
\hline Hubei & 1.00 & 1.00 & 1.00 & 1.00 & 1.00 & 1.00 & 1.00 & 1.00 & 1.00 & 1.00 & 1.00 & 1.00 & 1.00 \\
\hline Hunan & 0.96 & 1.00 & 0.94 & 0.97 & 0.97 & 0.97 & 0.99 & 1.00 & 0.99 & 0.97 & 0.95 & 0.96 & 0.96 \\
\hline Guangdong & 0.99 & 1.00 & 1.00 & 1.00 & 1.00 & 1.00 & 1.00 & 1.00 & 1.00 & 1.00 & 1.00 & 1.00 & 1.00 \\
\hline Guangxi & 0.97 & 0.94 & 0.92 & 0.90 & 0.95 & 0.95 & 0.93 & 0.90 & 0.88 & 0.81 & 0.75 & 0.72 & 0.73 \\
\hline Hainan & 1.00 & 1.00 & 1.00 & 1.00 & 1.00 & 1.00 & 1.00 & 1.00 & 1.00 & 1.00 & 1.00 & 1.00 & 1.00 \\
\hline Chongqing & 0.67 & 0.75 & 0.74 & 0.72 & 0.69 & 0.69 & 0.70 & 0.71 & 0.71 & 0.73 & 0.76 & 0.77 & 0.78 \\
\hline Sichuan & 0.86 & 0.81 & 0.80 & 0.83 & 0.85 & 0.86 & 0.88 & 0.87 & 0.87 & 0.89 & 0.91 & 0.92 & 0.93 \\
\hline Guizhou & 0.68 & 0.62 & 0.61 & 0.64 & 0.66 & 0.69 & 0.71 & 0.71 & 0.72 & 0.72 & 0.74 & 0.74 & 0.75 \\
\hline Yunnan & 0.74 & 0.70 & 0.70 & 0.73 & 0.75 & 0.75 & 0.74 & 0.73 & 0.75 & 0.75 & 0.73 & 0.76 & 0.77 \\
\hline Shaanxi & 0.63 & 0.62 & 0.63 & 0.64 & 0.64 & 0.65 & 0.65 & 0.66 & 0.65 & 0.64 & 0.63 & 0.62 & 0.62 \\
\hline Gansu & 0.97 & 0.91 & 0.92 & 0.99 & 1.00 & 1.00 & 0.98 & 0.94 & 0.90 & 0.88 & 0.89 & 0.86 & 0.89 \\
\hline Qinghai & 1.00 & 1.00 & 1.00 & 1.00 & 1.00 & 1.00 & 1.00 & 1.00 & 1.00 & 1.00 & 1.00 & 1.00 & 1.00 \\
\hline Ningxia & 0.84 & 0.95 & 0.90 & 0.90 & 0.89 & 0.93 & 0.85 & 0.85 & 0.81 & 0.83 & 0.82 & 0.82 & 0.83 \\
\hline Xinjiang & 0.73 & 0.73 & 0.74 & 0.73 & 0.74 & 0.73 & 0.70 & 0.69 & 0.70 & 0.71 & 0.71 & 0.70 & 0.71 \\
\hline Nationwide & 0.87 & 0.87 & 0.87 & 0.88 & 0.89 & 0.89 & 0.88 & 0.88 & 0.87 & 0.86 & 0.86 & 0.84 & 0.85 \\
\hline
\end{tabular}

As can be seen from Table 3, the provinces with the highest carbon emission performance in China were Shanghai, Fujian, Hubei, Hainan, and Qinghai. Their carbon emission performances in all years were one, and they were always at the frontier of production with optimal efficiency. In addition, in most years, the carbon emission performances of Guangdong and Tianjin were also one, showing high carbon emission efficiency. Among these provinces, Shanghai, Guangdong, Hubei, and Tianjin had advanced manufacturing levels. High-tech industries represented by the communication and information equipment manufacturing industry could achieve high economic output, while energy input was lower than industries with high energy consumption. Therefore, carbon emission efficiency was at a high level. The high carbon dioxide emission efficiency of Hainan and Fujian was mainly attributed to the structural emission reduction, the low proportion of industrialization, and the industrial structure dominated by the modern service industry. Qinghai was mainly attributed to the low proportion of industrialization. In a word, these provinces were the reference of other provinces, and also embodied their scientific development mode with highly coordinated economy and environment. Heilongiang entered the frontier after 2008, and Jiangsu had higher carbon emission efficiency as a whole. During the research period, provinces with low efficiency of carbon dioxide 
emissions were Hebei, Shanxi, Inner Mongolia, Jilin, Henan, Chongqing, Yunnan, Shaanxi, Guizhou, and Xinjiang. Referring to provinces in the production frontier and keeping the inputs unchanged, the "good" output of these provinces could increase about $30 \%$ in the current level, and carbon dioxide emissions from production process could decrease about 30\%. Although these provinces are rich in resources, they mainly develop industries with high energy consumption and heavy pollution, thus they had extensive economic development modes and low carbon dioxide emission efficiency.

For the dynamic evolution of the carbon dioxide emission efficiency of each province, the carbon emission efficiency of Beijing, Heilongjiang, Anhui, Sichuan, Chongqing, and Guizhou showed a significant improvement trend during the investigation period, which may have been related to government intervention. The carbon emission efficiency of Hebei, Shanxi, Inner Mongolia, Liaoning, Jilin, Henan, Gansu, and Ningxia showed an inverted "U" pattern in which the carbon emission efficiency first increased and then decreased. The carbon dioxide emission efficiency of Jiangxi and Guangxi was decreased in all periods. The carbon dioxide emission efficiency of Tianjin, Shanghai, Jiangsu, Zhejiang, Fujian, Shandong, Hubei, Hunan, Guangdong, Hainan, Yunnan, Shaanxi, Qinghai, and Xinjiang showed stable change with no obvious trend of increase or decrease.

\section{Measurement of Carbon Emission Efficiency under Meta-Frontier Model}

\subsection{Meta-Frontier Model}

As mentioned above, the hypothesis of technological homogeneity is not completely valid, thus the technology efficiency value under the meta-frontier, i.e., the CEP calculated by the DEA model, will have some deviations. Therefore, all these DMUs must be divided into different groups, and then the DEA method must be used to obtain group frontiers in different groups. However, the technical efficiency value under the group frontier is inaccurate as well, because it will be over-estimated for merely consulting technical levels within groups and neglecting the overall technical level. The ratio between them is the TGR of carbon emissions that shows technical differences between groups and the meta-frontier. This indicator overcomes the above shortcomings and makes an accurate comparison of carbon emission technology among different technical groups. As the result, we mainly used TGR to capture the provincial carbon emissions efficiency.

\subsection{Carbon Emission Performance under Group Frontier}

We divided China into three regions-eastern region, central region, and western region-regarded each region as a group frontier, and calculated the carbon emission performance in provinces of each region under the group frontier. The results are shown in Table 4.

As can be seen from Table 4, the provinces where carbon emission performance was one in most years under the group frontier were Tianjin, Shanghai, Fujian, Guangdong, Hainan, Jilin, Heilongjiang, Jiangxi, Hubei, Inner Mongolia, Guangxi, Chongqing, Sichuan, and Qinghai. These provinces all had high carbon emission efficiency. During the study period, Hebei, Shanxi, Henan, and Guizhou were the provinces with low carbon dioxide emission efficiency under the group frontier. For the dynamic evolution of carbon dioxide emission efficiency in each province under the group frontier, it can be seen that the carbon emission efficiency of Beijing, Anhui, Guizhou, and Shaanxi showed an obvious improvement trend during the study period. The carbon emission efficiency of Shanxi and Hunan showed an inverted " $U$ " pattern, which first increased and then decreased. The carbon dioxide emission efficiency of Hebei, Liaoning, Gansu, Ningxia, and Xinjiang decreased over time. The carbon dioxide emission efficiency of Tianjin, Shanghai, Jiangsu, Zhejiang, Fujian, Shandong, Guangdong, Hainan, Jilin, Heilongjiang, Jiangxi, Henan, Hubei, Inner Mongolia, Guangxi, Chongqing, Sichuan, Yunnan, and Qinghai showed a stable change and no obvious trend of increase or decrease.

The efficiency value of carbon emission performance in each province under the group frontier was greater than that under the meta-frontier. The efficiency values under the group frontier and the meta-frontier did not show too much difference. The carbon emission performances in provinces such 
as Inner Mongolia, Sichuan, and Qinghai were basically equal to one. Although those provinces are technically backward nationwide, they are on the technology frontier in the western region.

Table 4. Carbon emission performance in provinces of China under the group frontier (2004-2016).

\begin{tabular}{|c|c|c|c|c|c|c|c|c|c|c|c|c|c|}
\hline District & 2004 & 2005 & 2006 & 2007 & 2008 & 2009 & 2010 & 2011 & 2012 & 2013 & 2014 & 2015 & 2016 \\
\hline Beijing & 0.82 & 0.78 & 0.77 & 0.76 & 0.79 & 0.82 & 0.82 & 0.85 & 0.85 & 0.86 & 0.89 & 0.88 & 0.89 \\
\hline Tianjin & 1.00 & 1.00 & 1.00 & 1.00 & 1.00 & 0.96 & 1.00 & 1.00 & 1.00 & 1.00 & 1.00 & 1.00 & 1.00 \\
\hline Hebei & 0.85 & 0.83 & 0.79 & 0.80 & 0.79 & 0.81 & 0.81 & 0.81 & 0.79 & 0.79 & 0.80 & 0.73 & 0.79 \\
\hline Liaoning & 1.00 & 1.00 & 1.00 & 1.00 & 1.00 & 1.00 & 0.99 & 1.00 & 0.93 & 0.92 & 0.92 & 0.81 & 0.80 \\
\hline Shanghai & 1.00 & 1.00 & 1.00 & 1.00 & 1.00 & 1.00 & 1.00 & 1.00 & 1.00 & 1.00 & 1.00 & 1.00 & 1.00 \\
\hline Jiangsu & 0.95 & 1.00 & 1.00 & 0.98 & 0.93 & 0.94 & 0.94 & 0.96 & 0.96 & 0.97 & 0.97 & 0.93 & 0.96 \\
\hline Zhejiang & 0.93 & 0.92 & 0.90 & 0.89 & 0.91 & 0.94 & 0.90 & 0.90 & 0.91 & 0.91 & 0.91 & 0.92 & 0.92 \\
\hline Fujian & 1.00 & 1.00 & 1.00 & 1.00 & 1.00 & 1.00 & 1.00 & 1.00 & 1.00 & 1.00 & 1.00 & 1.00 & 1.00 \\
\hline Shandong & 0.93 & 0.90 & 0.87 & 0.87 & 0.87 & 0.87 & 0.88 & 0.89 & 0.91 & 0.89 & 0.89 & 0.82 & 0.88 \\
\hline Guangdong & 1.00 & 1.00 & 1.00 & 1.00 & 1.00 & 1.00 & 1.00 & 1.00 & 1.00 & 1.00 & 1.00 & 1.00 & 1.00 \\
\hline Hainan & 1.00 & 1.00 & 1.00 & 1.00 & 1.00 & 1.00 & 1.00 & 1.00 & 1.00 & 1.00 & 1.00 & 1.00 & 1.00 \\
\hline Shanxi & 0.68 & 0.66 & 0.70 & 0.73 & 0.74 & 0.74 & 0.72 & 0.68 & 0.64 & 0.64 & 0.61 & 0.62 & 0.63 \\
\hline Jilin & 1.00 & 1.00 & 1.00 & 1.00 & 1.00 & 1.00 & 1.00 & 1.00 & 1.00 & 1.00 & 1.00 & 1.00 & 1.00 \\
\hline Heilongjiang & 1.00 & 1.00 & 1.00 & 1.00 & 1.00 & 1.00 & 1.00 & 1.00 & 1.00 & 1.00 & 1.00 & 1.00 & 1.00 \\
\hline Anhui & 0.84 & 0.88 & 0.95 & 0.96 & 0.99 & 1.00 & 1.00 & 1.00 & 1.00 & 1.00 & 1.00 & 1.00 & 1.00 \\
\hline Jiangxi & 1.00 & 1.00 & 1.00 & 1.00 & 1.00 & 1.00 & 1.00 & 1.00 & 1.00 & 1.00 & 1.00 & 1.00 & 1.00 \\
\hline Henan & 0.83 & 0.83 & 0.80 & 0.81 & 0.84 & 0.84 & 0.83 & 0.81 & 0.79 & 0.78 & 0.79 & 0.80 & 0.79 \\
\hline Hubei & 1.00 & 1.00 & 1.00 & 1.00 & 1.00 & 1.00 & 1.00 & 1.00 & 1.00 & 1.00 & 1.00 & 1.00 & 1.00 \\
\hline Hunan & 0.98 & 1.00 & 0.95 & 0.97 & 0.98 & 0.99 & 1.00 & 1.00 & 1.00 & 1.00 & 0.97 & 0.96 & 0.97 \\
\hline Inner Mongolia & 1.00 & 1.00 & 1.00 & 1.00 & 1.00 & 1.00 & 1.00 & 1.00 & 1.00 & 1.00 & 1.00 & 1.00 & 1.00 \\
\hline Guangxi & 1.00 & 1.00 & 1.00 & 1.00 & 1.00 & 1.00 & 1.00 & 1.00 & 1.00 & 1.00 & 1.00 & 1.00 & 1.00 \\
\hline Chongqing & 0.90 & 1.00 & 1.00 & 1.00 & 1.00 & 1.00 & 1.00 & 1.00 & 1.00 & 1.00 & 1.00 & 1.00 & 1.00 \\
\hline Sichuan & 1.00 & 1.00 & 1.00 & 1.00 & 1.00 & 1.00 & 1.00 & 1.00 & 1.00 & 1.00 & 1.00 & 1.00 & 1.00 \\
\hline Guizhou & 0.71 & 0.68 & 0.67 & 0.66 & 0.67 & 0.70 & 0.73 & 0.76 & 0.80 & 0.81 & 0.82 & 0.81 & 0.81 \\
\hline Yunnan & 0.84 & 0.88 & 0.89 & 0.89 & 0.86 & 0.82 & 0.83 & 0.83 & 0.87 & 0.88 & 0.89 & 0.88 & 0.88 \\
\hline Shaanxi & 0.84 & 0.86 & 0.86 & 0.89 & 0.93 & 0.89 & 0.96 & 0.98 & 0.99 & 0.97 & 0.95 & 0.94 & 0.96 \\
\hline Gansu & 1.00 & 1.00 & 1.00 & 1.00 & 1.00 & 1.00 & 1.00 & 1.00 & 1.00 & 0.99 & 0.99 & 0.95 & 0.97 \\
\hline Qinghai & 1.00 & 1.00 & 1.00 & 1.00 & 1.00 & 1.00 & 1.00 & 1.00 & 1.00 & 1.00 & 1.00 & 1.00 & 1.00 \\
\hline Ningxia & 1.00 & 0.95 & 0.90 & 0.90 & 0.89 & 0.95 & 0.86 & 0.87 & 0.83 & 0.85 & 0.84 & 0.84 & 0.83 \\
\hline Xinjiang & 1.00 & 1.00 & 1.00 & 1.00 & 1.00 & 1.00 & 1.00 & 1.00 & 0.99 & 0.95 & 0.95 & 0.96 & 0.96 \\
\hline Nationwide & 0.94 & 0.94 & 0.94 & 0.94 & 0.94 & 0.94 & 0.94 & 0.94 & 0.94 & 0.94 & 0.94 & 0.93 & 0.94 \\
\hline
\end{tabular}

\subsection{Technology Gap Ratio of Carbon Emissions (TGR)}

TGR reflects the technological gap in carbon emissions among different provinces of China, as shown in Table 5.

As can be seen from Table 5, when the carbon emission technology gap ratio was used to calculate the carbon emission performance, the carbon emission performances of Beijing, Tianjin, Shanghai, Jiangsu, Zhejiang, Fujian, Guangdong, Hainan, Shanxi, Hubei, and Qinghai were one in most years; in general, these provinces have always been at the frontier of production, and their efficiency is relatively optimal. It can be seen that most of them are eastern provinces. The provinces with lower carbon efficiency in the study period were Jilin, Inner Mongolia, Guangxi, Chongqing, Shaanxi, and Xinjiang. It can be seen that most of them are western provinces. For the dynamic evolution of carbon dioxide emission efficiency of each province, the carbon emission efficiency of Hebei, Shandong, Heilongjiang, and Sichuan showed an obvious improvement trend during the investigation period. The carbon emission efficiency of Jilin, Jiangxi, Henan, Inner Mongolia, Guizhou, and Gansu showed an inverted "U" pattern, which first increased and then decreased. The carbon emission efficiency of Guangxi and Shaanxi decreased in the sample period. The carbon emission efficiency of Beijing, Tianjin, Liaoning, Shanghai, Jiangsu, Zhejiang, Fujian, Guangdong, Hainan, Shanxi, Anhui, Hubei, Hunan, Chongqing, Yunnan, Qinghai, Ningxia, and Xinjiang showed a stable change and no obvious trend of increase or decrease. From the perspective of the differences among different regions, the average annual carbon emission efficiency of the eastern region was highest. The eastern region is very close to the production frontier, and the change trend was relatively stable during the sample period, indicating that the 
carbon emission efficiency of all the eastern provinces was relatively high. The average annual carbon emission efficiency of the central region was lower than that of the eastern region, but it was at a higher level compared to the national average. In addition, the carbon dioxide emission efficiency of the central region showed an inverted " $U$ " pattern, which first increased and then decreased. The carbon emission efficiency increased during 2004-2008 and decreased during 2009-2016 in the central region. The annual average carbon emission efficiency of the western region was the lowest, which was lower than the national average, indicating that the carbon emission efficiency of all provinces in the western region was low. In addition, the carbon dioxide emission efficiency of the western region showed a unilateral downward trend during the sample period.

Table 5. Technology gap ratio of carbon emissions (TGR) in provinces of China (2004-2016).

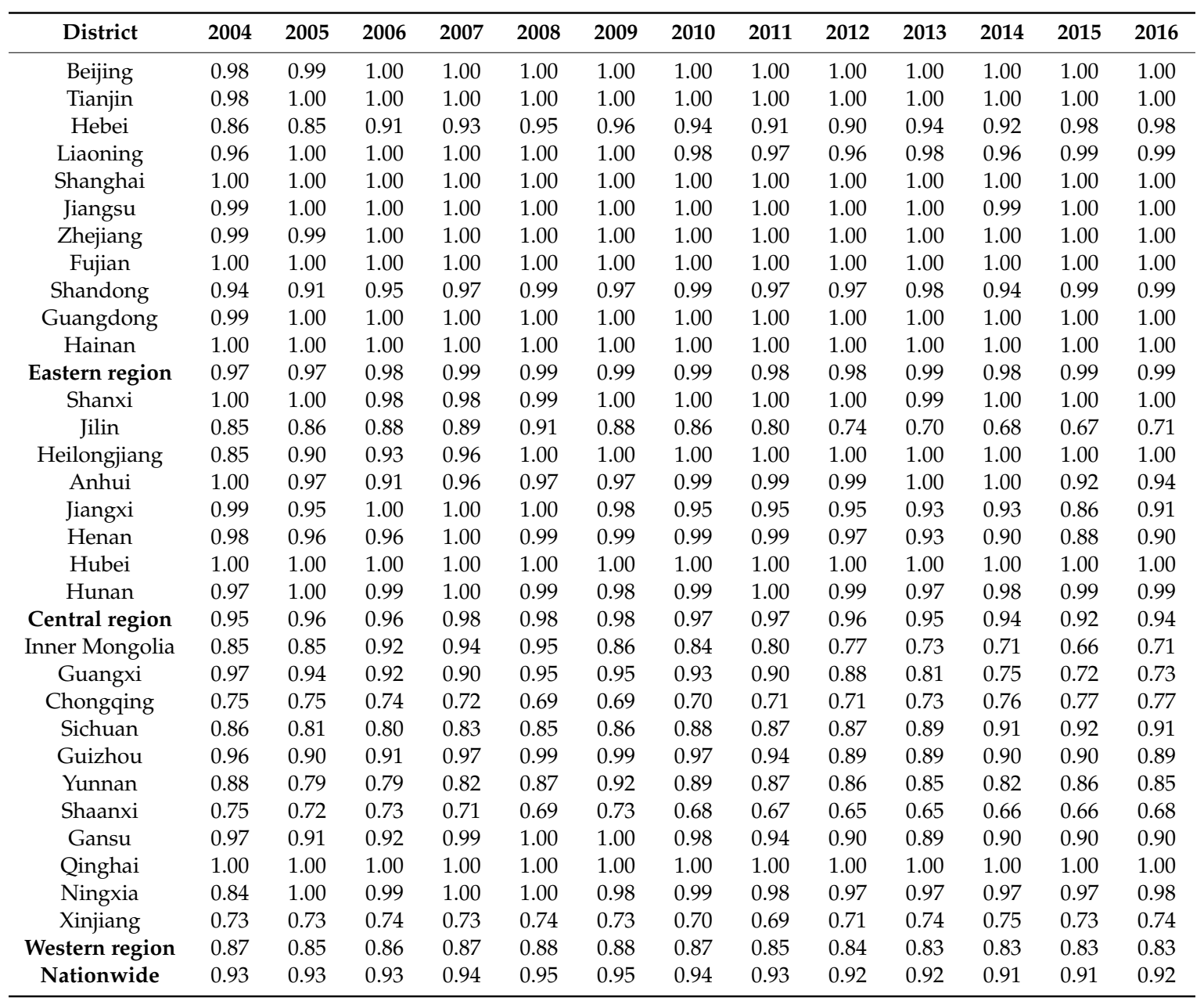

The provincial carbon emissions efficiency calculated with the TGR was inconsistent with the research conclusions of Dong et al. [33], Huang and Meng [34], Wang and Zhang [35], and basically consistent with the research conclusions of Wang et al. [36]. For example, Dong et al. calculated China's regional carbon efficiency index with the translog stochastic frontier model. The study found that China's carbon emission efficiency index showed an upward trend during the study period. The carbon emission efficiency index of the three regions decreased successively. The convergence test showed that the carbon emission efficiency showed a convergence trend in the whole country and in the three regions. The carbon emission efficiency converged fastest in the central region and slowest in the western region. The results of our estimation based on TGR show that the carbon emissions efficiency of the eastern region had a relatively stable change trend during the sample period with no obvious upward or downward trend. The central and western regions all eventually 
showed a downward trend, i.e., no convergence. We believe that there were two reasons for this. First, the aforementioned scholars used the translog stochastic frontier model to calculate the provincial carbon emissions efficiency in China, while we used the TGR, which combines the meta-frontier and the group frontier. As we mentioned in the Methods section, TGR is more reasonable than traditional methods such as single-factor carbon emission efficiency and the Malmquist index because it allows for comparing the difference in carbon emission performance between different groups or regions in China. Second, the studies mentioned above mainly analyzed China's provincial carbon emission performance before 2010, and the sample period we analyzed was from 2004 to 2016. Therefore, our research results reflect the changes in China's provincial carbon emissions efficiency in recent years. As a result, this paper is a supplement to the existing research in this field and is conducive to accurately understanding the changes in China's provincial carbon emission efficiency in recent years.

\section{Analysis of Factors Influencing Carbon Emissions Efficiency}

\subsection{Tobit Model}

To solve the problem of biased and inconsistent parameter estimation, scholars proposed the two-stage model based on DEA analysis. The first stage measures the efficiency value of a DMU by using the DEA model, and the second stage builds the Tobit model to conduct regression analysis by regarding the efficiency value as dependent variables and the influencing factors of the efficiency value as the independent variables:

$$
\begin{gathered}
\mathrm{y}_{i}^{*}=\beta^{T} x_{i}+e_{i} \\
y_{i}=y_{i}^{*}, i f=y_{i}^{*}>0 \\
y_{i}=0, i f=y_{i}^{*} \leq 0 \\
e_{i}=N\left(0, \delta^{2}\right), i=1,2,3 \ldots, n
\end{gathered}
$$

In the formula above, $y_{i}^{*}$ is an independent variable, $x_{i}$ is a dependent variable, and $\beta^{T}$ is the correlation index. When $y_{i}^{*}>0, y_{i}=y_{i}^{*}>0, y_{i}$ is unlimited observation value and should be taken on the real value; when $y_{i}^{*} \leq 0, y_{i}=0, y_{i}$ is limited observation value and should be taken on the value of 0 . This article chose the panel data Tobit regression model under random effect to analyze the influencing factors of carbon emissions efficiency.

According to the above analysis and the conclusion of the influencing factors of carbon emission efficiency, the regression model was designed as follows:

$$
\begin{aligned}
& C E P_{i t}=\beta_{1}+\beta_{2} R_{J G D P}+\beta_{3} R \operatorname{SGDP}^{2}{ }_{i t}+\beta_{4} S E C T_{i t}+\beta_{5} F D I_{i t}+\beta_{6} \mathrm{OPEN}_{i t}+\beta_{7} E I N T_{i t}+\beta_{8} C L \\
& +\beta_{9} G O V_{i t}+\beta_{10} P R O_{i t}+u_{i t} \\
& T G R_{i t}=\beta_{1}+\beta_{2} R J G D P_{i t}+\beta_{3} R J G D P^{2}{ }_{i t}+\beta_{4} S E C T_{i t}+\beta_{5} F D I_{i t}+\beta_{6} O P E N_{i t}+\beta_{7} E I N T_{i t}+\beta_{8} C L \\
& +\beta_{9} G O V_{i t}+\beta_{10} P R O_{i t}+u_{i t}
\end{aligned}
$$

In this model, $\beta_{i}$ is the constant term in the regression equation, $\beta_{2}-\beta_{10}$ is the regression coefficients of the influencing factors, and $u_{i t}$ is a random error term. Referring to existing literature, we chose economic scale (RJGDP), industrial structure (SECT), foreign direct investment (FDI), opening-up degree (OPEN), energy intensity (EINT), capital-labor ratio (CL), government interference (GOV), and ownership structure (PRO) as independent variables. Details are as follow.

Economic scale. Economic scale is a sign of the state and potential of regional economic development. To measure the economic development level of a region, we should not only analyze whether the economic scale has been expanded but also examine whether the economic quality has been improved. If the economic scale of a region expands, it will provide a rich material basis for scientific and technological innovation, thus promoting the progress of environmental technology and ultimately leading to the improvement of carbon emission efficiency. In addition, with the economic development 
and the improvement of the level, the public will have higher requirements on the environmental quality, which will further promote optimization and upgrading of the industrial structure, thus driving the improvement of carbon emission efficiency. However, if the economic development of a region is an extensive growth driven by factors, and the economic quality does not improve with the expansion of economic scale, the increase of resource input and energy consumption will lead to the corresponding increase of pollution emissions. Thus, the effect of economic size is uncertain.

Industrial structure. Industry is the leading industry in China's economy, accounting for more than $80 \%$ of carbon emissions, especially the heavy industry represented by oil processing, coking, and nuclear fuel processing. This kind of industry is characterized by high energy consumption and high emissions. If energy conservation and emission reduction are implemented, it will be of great significance to the low-carbon development of the entire industry. The bad effect of heavy industrial structure on environmental pollution is especially obvious. Therefore, it is necessary to analyze the impact of heavy industry structure on carbon emissions.

Foreign direct investment. The influence mechanism of FDI on the provincial carbon emission efficiency in China is relatively complex. On the one hand, through foreign direct investment, many foreign advanced technologies and management methods can be introduced to improve the carbon emission efficiency. However, on the other hand, some capital-intensive and labor-intensive foreign-funded enterprises may be transferred from developed countries to developing countries for their own interests. These capital-intensive and labor-intensive enterprises will hinder the growth of carbon emission efficiency. In addition, while expanding the production scale and the total output of the host country, FDI also consumes more resources and energy and emits more environmental pollutants.

Opening-up degree. Foreign trade is one of the three engines driving the growth of national economy, thus countries all over the world pay special attention to the development of their own trade. With the deepening of trade, environmental problems come along, and the large increase of greenhouse gas emissions represented by carbon dioxide has gradually attracted the attention of all countries. Unreasonable foreign trade can increase energy consumption, and the increase of energy consumption has a positive impact on carbon emissions. At the same time, the increase of trade dependence also has a negative impact on the improvement of carbon emission efficiency, thus it is necessary to select this factor for analysis.

Energy intensity. A lot of emissions are caused by energy consumption, which will increase the undesired output and thus reduce the carbon emission efficiency. Therefore, the energy consumption mainly affects the technical efficiency change, and then will influence carbon emission efficiency. Although energy intensity can reflect the status of environmental pollution, it can also reflect the status of economic growth at the same time. This is because more energy consumption indicates economic development, and carbon dioxide emissions are also increasing, thus the direction of its influence on carbon emission efficiency cannot be determined.

Capital-labor ratio. Capital-labor ratio is the basis of regional economic development and environmental friendliness, which largely determines the level of economic development and the efficiency of pollution gas emission.

Government interference. For a long time, most of China's energy resources was controlled by state-owned enterprises. On the one hand, the government's excessive intervention of market is not conducive to China's environmental efficiency. On the other hand, the government regulation will help promote the adjustment of industrial structure. Especially in recent years, in order to promote energy conservation and emissions reduction targets, the government adopted the measures that combine rewards and punishment methods, which improves the efficiency of carbon dioxide emissions greatly, thus it is necessary to select this factor for analysis.

Ownership structure. China's ownership structure is also changing with the deepening of reform and opening up, and the reform of state-owned enterprises is a typical representative of the change of China's ownership structure. State-owned enterprises hold a large number of resources, which easily lead to the deviation of energy prices from market prices. The ownership and management 
rights of private enterprises are highly unified, and the capital owners will pursue the maximization of capital use efficiency. The resource utilization efficiency of state-owned enterprises is lower than that of private enterprises, and a large amount of carbon dioxide emissions will be generated in the production process, resulting in low carbon dioxide emission efficiency. Definition and description of correlated variables are given in Table 6.

Table 6. Definition and description of relevant variables.

\begin{tabular}{ccc}
\hline Variable Name & Definition of Variable & Unit \\
\hline Economic scale & Per capita gross domestic product (GDP) & 10,000 Yuan RMB \\
Industrial structure & Percent of secondary industry in GDP \\
Ownership structure & Percent of Stated-owned employees in year-end & \\
& employees & Standard coal ton/ \\
Energy intensity & Real energy consumption per unit of GDP & 10,000 Yuan RMB \\
Opening-up degree & Percent of import-export trade in GDP & 100 million dollar \\
Foreign direct investment & Volume of direct foreign investment & 10,000 Yuan RMB/ person \\
Capital-labor ratio & The ratio between capital stock and number of employee & Percent of government expenditure in GDP \\
Government interference & P & \\
\hline
\end{tabular}

In addition, the data in Table 6 come from China Economics Statistical Yearbook (2005-2017), China Energy Statistical Yearbook, China Labor Statistical Yearbook and China Commerce Yearbook.

\subsection{Regression Result and Analysis}

According to the data in 30 provinces during the years 2004-2016, regression was carried out on CEP and TGR in three regions by using the Stata12.0 software and the panel data Tobit model. Specifically, the eastern region includes Beijing, Tianjin, Hebei, Liaoning, Shanghai, Jiangsu, Zhejiang, Fujian, Shandong, Guangdong, and Hainan; the central region includes Shanxi, Jilin, Heilongjiang, Anhui, Jiangxi, Henan, Hubei, and Hunan; the western region includes Inner Mongolia, Guangxi, Chongqing, Sichuan, Guizhou, Yunnan, Shaanxi, Gansu, Qinghai, Ningxia, and Xinjiang, and thus the data we used to estimate were panel data. We used the LLC method to test the stability of the data and found that all of the variables were stable. Due to the limitation of space, we did not report the results of the stationary test. Regression analyses of CEP in China are shown in Table 7.

Table 7. Regression analysis of carbon emission performance (CEP) in eastern, central, and western regions of China.

\begin{tabular}{ccccccc}
\hline \multirow{2}{*}{ Influencing Factors } & \multicolumn{2}{c}{ Eastern Region } & \multicolumn{2}{c}{ Central Region } & \multicolumn{2}{c}{ Western Region } \\
\cline { 2 - 7 } & Coefficient & $\boldsymbol{P}$ & Coefficient & $\boldsymbol{P}$ & Coefficient & $\boldsymbol{P}$ \\
\hline Constant term & $1.0041^{* * *}$ & 0.0000 & $1.2166^{* * *}$ & 0.0000 & $0.9216^{* * *}$ & 0.0000 \\
Economic scale & $0.0037^{* * *}$ & 0.6980 & $0.0984^{* * *}$ & 0.0030 & $0.1091^{* * *}$ & 0.0000 \\
Square of economic scale & $0.0027^{* * *}$ & 0.0070 & $0.0286^{* * *}$ & 0.0000 & 0.0011 & 0.7240 \\
Industrialstructure & $-0.3154^{* *}$ & 0.0210 & $-0.5202^{* * *}$ & 0.0010 & $-0.5901^{* * *}$ & 0.0030 \\
Ownership structure & 0.0383 & 0.7440 & $-0.9474^{*}$ & 0.0720 & -0.1639 & 0.6920 \\
Energy intensity & $-0.2248^{* * *}$ & 0.0060 & $-0.0442^{*}$ & 0.0910 & -0.0095 & 0.4950 \\
Capital-labor ratio & -0.0021 & 0.3340 & $-0.0394^{* * *}$ & 0.0000 & $-0.0133^{* *}$ & 0.0390 \\
Opening-up degree & $0.1052^{* *}$ & 0.5640 & $7.4163^{* * *}$ & 0.0000 & $2.5360^{* *}$ & 0.0410 \\
FDI & $-0.0005^{* * *}$ & 0.0000 & $-0.0008^{* *}$ & 0.0330 & 0.0002 & 0.1050 \\
Government interference & $-0.2328^{* * *}$ & 0.0060 & -0.1999 & 0.1580 & $0.0744^{*}$ & 0.0990 \\
\hline
\end{tabular}

Note: ${ }^{* * *},{ }^{* *},{ }^{*}$ represents passing the test in a significant level of $1 \%, 5 \%$, and $10 \%$, respectively. FDI $=$ foreign direct investment.

As can be seen from the regression results in Table 7, when CEP was used to measure provincial carbon emission efficiency in Chinese provinces, ownership structure, energy intensity, FDI, and government interference were not significant in most regression equations. Therefore, these explanatory variables were removed. The adjusted regression results are shown in Table 8. 
Table 8. Adjusted regression analysis of CEP in eastern, central, and western regions of China.

\begin{tabular}{ccccccc}
\hline \multirow{2}{*}{ Influencing Factors } & \multicolumn{2}{c}{ Eastern Region } & \multicolumn{2}{c}{ Central Region } & \multicolumn{2}{c}{ Western Region } \\
\cline { 2 - 7 } & Coefficient & $\boldsymbol{P}$ & Coefficient & $\boldsymbol{P}$ & Coefficient & $\boldsymbol{P}$ \\
\hline Constant term & $1.0112^{* * *}$ & 0.0000 & $1.3277^{* * *}$ & 0.0000 & $0.9835^{* * *}$ & 0.0000 \\
Economic scale & $0.0085^{* *}$ & 0.0952 & $0.1054^{* * *}$ & 0.0000 & $0.1132^{* * *}$ & 0.0000 \\
Square of economic scale & $0.0031^{* * *}$ & 0.0010 & $0.0219^{* * *}$ & 0.0000 & 0.0018 & 0.8331 \\
Industrialstructure & $-0.3326^{* * *}$ & 0.0014 & $-0.5739^{* * *}$ & 0.0000 & $-0.6327^{* * *}$ & 0.0010 \\
Capital-labor ratio & $-0.0036^{* * *}$ & 0.3877 & $-0.0414^{* * *}$ & 0.0000 & $-0.0318^{* *}$ & 0.0422 \\
Opening-up degree & $0.1734^{* * *}$ & 0.6792 & $8.6313^{* * *}$ & 0.0000 & $2.9980^{* *}$ & 0.0378 \\
\hline
\end{tabular}

Note: ${ }^{* * *}, * * * *$ represents passing the test in a significant level of $1 \%, 5 \%$, and $10 \%$, respectively.

Table 8 shows the adjusted regression results, and it can be found that:

The square coefficients of economic scale in eastern, central, and western regions of China were all positive. The coefficients in the eastern and the central regions were significant, while that in the western region was insignificant, which suggests that the CEP in the eastern and the central regions presented the U-type feature along with the growth of per capita GDP and would increase significantly after the inflection point.

The variation coefficients of industrial structure in the three regions were significantly negative. In an economy, with a higher proportion of low-energy industries, less energy consumption, lower carbon emissions, and higher CEP will be achieved. The higher the proportion of the secondary industry in GDP is, the lower the CEP will be. By comparing the coefficient of industrial structure, the absolute value in the western region was the biggest, followed by the central region, and the eastern region had the lowest one.

Capital-labor ratio reflects element endowment, and its coefficients in the regression model in the central and the western regions were significantly negative, which suggests that with the improvement of the capital-labor ratio, the economic structure of the two regions had the tendency of converting from a labor-intensive model to a capital-intensive model. The regression coefficient in the eastern region was negative as well, but it was insignificant.

The coefficient of the opening-up degree in models of the central and the western regions was larger and significantly positive, which indicates that more international trade could promote the introduction of advanced technology, management skills, and new equipments, bringing huge positive effects to the improvement of CEP.

In addition, the estimated results of all variables in Tables 7 and 8 were basically the same, but the significance of some variables in Table 8 was slightly increased, indicating that the regression results were robust.

The regression analysis of TGR in China is shown in Table 9.

Table 9. Regression analysis of TGR in eastern, central, and western regions of China.

\begin{tabular}{ccccccc}
\hline \multirow{2}{*}{ Influencing Factor } & \multicolumn{2}{c}{ Eastern Region } & \multicolumn{2}{c}{ Central Region } & \multicolumn{2}{c}{ Western Region } \\
\cline { 2 - 7 } & Coefficient & $\boldsymbol{P}$ & Coefficient & $\boldsymbol{P}$ & Coefficient & $\boldsymbol{P}$ \\
\hline Constant term & $1.1130^{* * *}$ & 0.0000 & $1.5176^{* * *}$ & 0.0000 & $0.9891^{* * *}$ & 0.0000 \\
Economic scale & $0.0066^{* *}$ & 0.5790 & $0.0960^{* * *}$ & 0.0010 & $0.0582^{* *}$ & 0.0280 \\
Square of economic scale & $0.0203^{* * *}$ & 0.0030 & $0.0288^{* * *}$ & 0.0000 & 0.0011 & 0.7240 \\
Industrial structure & $-0.3492^{* *}$ & 0.0120 & $-0.4526^{* * *}$ & 0.0000 & $-0.4059^{* *}$ & 0.0480 \\
Ownership structure & $-0.5253^{* * *}$ & 0.0030 & $-1.2216^{* * *}$ & 0.0020 & $-0.6553^{*}$ & 0.0530 \\
Energy intensity & $-0.0308^{* *}$ & 0.7990 & $-0.0446^{* *}$ & 0.0540 & -0.0152 & 0.2690 \\
Capital-labor ratio & $-0.0064^{* *}$ & 0.0340 & $-0.0456^{* * *}$ & 0.0000 & $-0.0252^{* * *}$ & 0.0030 \\
Degree of opening-up & $1.0127^{* * *}$ & 0.0000 & $5.1576^{* * *}$ & 0.0020 & $2.5360^{* *}$ & 0.0410 \\
FDI & $-0.0002^{*}$ & 0.0980 & -0.0003 & 0.2900 & 0.0001 & 0.3220 \\
Government interference & -0.0483 & 0.6530 & $-0.2085^{*}$ & 0.0760 & $0.0744^{*}$ & 0.0990 \\
\hline
\end{tabular}

Note: ${ }^{* * *}, * * *$ represents passing the test in a significant level of $1 \%, 5 \%$, and $10 \%$, respectively. 
As can be seen from the regression results in Table 9, when TGR was used to measure provincial carbon emission efficiency in Chinese provinces, energy intensity, FDI, and government interference were not significant in most regression equations. Therefore, these explanatory variables were removed. The adjusted regression results are shown in Table 10.

Table 10. Adjusted regression analysis of TGR in eastern, central, and western regions of China.

\begin{tabular}{ccccccc}
\hline \multirow{2}{*}{ Influencing Factor } & \multicolumn{2}{c}{ Eastern Region } & \multicolumn{2}{c}{ Central Region } & \multicolumn{2}{c}{ Western Region } \\
\cline { 2 - 7 } & Coefficient & $\boldsymbol{P}$ & Coefficient & $\boldsymbol{P}$ & Coefficient & $\boldsymbol{P}$ \\
\hline Constant term & $1.5022^{* * *}$ & 0.0000 & $1.4626^{* * *}$ & 0.0000 & $0.1029^{* * *}$ & 0.0000 \\
Economic scale & $0.0093^{*}$ & 0.0821 & $0.1127^{* * *}$ & 0.0000 & $0.0497^{* * *}$ & 0.0079 \\
Square of economic scale & $0.0314^{* * *}$ & 0.0000 & $0.0528^{* * *}$ & 0.0000 & 0.0004 & 0.5742 \\
Industrial structure & $-0.4128^{* * *}$ & 0.0073 & $-0.6626^{* * *}$ & 0.0000 & $-0.4171^{* *}$ & 0.0325 \\
Ownership structure & $-0.6651^{* * *}$ & 0.0000 & $-1.4144^{* * *}$ & 0.0082 & $-0.6792^{* *}$ & 0.0402 \\
Capital-labor ratio & $-0.0081^{* *}$ & 0.0129 & $-0.0751^{* * *}$ & 0.0000 & $-0.0621^{* *}$ & 0.0140 \\
Degree of opening-up & $1.4259^{* * *}$ & 0.0000 & $4.7722^{* * *}$ & 0.0011 & $2.9270^{* *}$ & 0.0382 \\
\hline
\end{tabular}

Note: $* * * * *, *$ represents passing the test in a significant level of $1 \%, 5 \%, 10 \%$ respectively.

Table 10 shows the adjusted regression results, and it can be found that:

In the eastern and the central region of China, the coefficient of the economic scale square was significantly positive, which shows that with the growth of per capita GDP, the carbon emission technology in the two regions presented U-type features of descending first and then ascending after. The economic scale square coefficient was insignificant in the western region, but the economic scale coefficient was significantly positive, which suggests that the carbon emission technology improved along with the growth of per capita GDP in this region. The significant negative variable coefficient of industrial structure in these three regions suggests that the constant increase of the proportion of secondary industry would lead to the increase of carbon emissions and would have negative impacts on the improvement of the carbon emission technology. Variables of ownership structure in these three regions all had significant negative effects on the carbon emission technology, which indicates that the continuous decrease of the ratio of public-owned enterprises effectively enhanced regional carbon emission technology. The coefficient of the capital-labor ratio variables reflected factor-endowment, and the absolute values of them were all small, which shows that it had little effect on the carbon emission technology. In the three regions, the opening-up degree had significant positive influence on the carbon emission technology. In addition, the estimated results of all variables in Tables 9 and 10 were basically the same, but the significance of some variables in Table 10 was slightly increased, indicating that the regression results were robust.

Combined with the results in Tables 8 and 10, it can be seen that, whether CEP or TGR is used as the provincial carbon emission efficiency measurement index, energy intensity, FDI, and government interference were not key factors affecting the carbon emission efficiency of the three regions in China. Economic scale, industrial structure, ownership structure, capital-labor ratio, and degree of opening-up had different effects on the carbon emission efficiency of different regions. Wang et al. [36], Zhang et al. [37], Luukkanen J and Kaivo-Oja [38], Ang [39], and Fan et al. [40] mainly examined economic scale, population scale, industrial structure, foreign openness, energy efficiency, and other traditional factors that may influence the efficiency of carbon emissions. In addition to these previously studied factors, this paper examined ownership structure and government interference, and found that these factors influence carbon efficiency in parts of China. Therefore, compared with previous studies, this paper may be more comprehensive and accurate in studying the influencing factors of China's provincial carbon emission efficiency. The research in this paper is a supplement to the existing research in this field and has certain reference significance for other developing countries similar to China. 


\section{Conclusions and Discussion}

\subsection{Main Conclusions}

Overall, the total carbon emissions and the per capita carbon emissions were on the rise year by year from 2004 to 2016. The national carbon emissions and the national per capita carbon intensity had risen to 3.582 billion tons and 2.71 tons per person in 2016 from the 1.288 billion tons and 1.01 tons per person in 2004. However, the carbon intensity showed an annually decreasing tendency, which dropped to 0.88 tons from 1.22 tons every ten thousand RMB.

Distinct differences existed in carbon emission performance in the eastern, the central, and the western regions of China under the meta-frontier measured by the DEA model, and the eastern region had the highest carbon emission performance, followed by the central (featured by an inverted U-type) and the western regions. The differences mainly lie in technology efficiency, but not scale efficiency.

Differences among regions were less obvious under the group frontier, and the carbon emission performances of the three regions were all above 0.9 , which was higher than that under the meta-frontier. However, the group frontier only considered the CEP under the technology condition within the group, thus the CEP of the central and the western regions was over estimated.

The ratio of CEP under the meta-frontier and the group frontier was the TGR of carbon emissions, which was used for the cross-regional comparison of carbon technology. The eastern region had the most advanced carbon technology. The central region was very close to that, while the western region had fallen behind.

The variables of scale economy, scale economy square, industrial structure, opening-up degree, FDI, energy intensity, government interference, ownership structure, and capital-labor ratio all had different impacts on the carbon emission efficiency.

\subsection{Discussion}

From the simple statistical indicators, China's work on emission reduction has been effective, although there are regional differences. These differences are more pronounced for total factor carbon emissions efficiency, which includes more comprehensive variables.

The results of the basic DEA model show that the provinces with the highest carbon emission performance can be found in both underdeveloped regions and developed southeastern coastal regions. High carbon emission performance in underdeveloped areas is due to its low industrialization level. However, the high carbon emission performance in developed areas is exciting-these provinces have achieved both high industrialization levels and environmental protection levels. This also shows that the trend of carbon emissions performance should rise first and then decline. The results of the central and the western region provinces proved this trend. Specifically, when TGR was used to calculate the carbon emission performance, the energy consumption and the carbon dioxide emissions in the eastern region were very high. However, in recent years, the optimization of industrial structure and energy consumption structure, a large number of capital and technology advantages accumulated by early rapid economic development, the use of clean energy and environmental protection technology, and the policies that strengthened the importance of environmental protection all enabled the economic development of the eastern region to be positively coupled with the carbon emission efficiency. Carbon efficiency in the central region is improving at a slower rate than in the east. Central provinces are rich in resources. Under the impetus of the "rise of central China" strategy, in order to realize the rapid economic development, most provinces are building infrastructure and heavy industry. However, the development of the second and third industries lacks the support of advanced technology and management, and the economic growth relies too much on resource consumption, leading to a significant increase in carbon dioxide emissions, thus the carbon emission efficiency improves slowly. The western region is the least efficient. Although the western region is very rich in natural resources, the region's economic foundation is weak. The strategy of "developing the west" not only brings development opportunities to the west region but also brings great challenges to the fragile ecological 
environment. The transfer of high energy consumption and high pollution industries from the east to the west makes the energy consumption and carbon emission in the west increase rapidly. Overall, the level of carbon dioxide emission efficiency varies from region to region. The national carbon dioxide emission efficiency remains relatively stable, but further improvements are needed.

Based on the regression results, the factors of static carbon emission efficiency were successfully identified, but the dynamic factors were not. In other words, the identified factors have a long-term effect on carbon efficiency. The average carbon efficiency of a country can be improved if long-term measures are taken to influence these factors (in the right direction).

The adoption of policies must also be tailored to the country's own circumstances. Stern and Jotzo [41] assessed the difficulty of achieving carbon reduction targets in China and India and analyzed the impact of national conditions on the effectiveness of carbon reduction policies. The policy maker should also pay attention to the impacts of economic development stages on carbon emissions.

\section{Policy Suggestions}

Accordingly, based on the analysis above, this article proposes the following suggestions and recommendations aimed at the improvement of carbon emission efficiency for a developing country.

\subsection{Optimization of Industrial Structure}

Poor industrial foundation, too many high energy-consuming enterprises, and unreasonable industrial distribution are the leading causes of large carbon emissions and low carbon emission efficiencies in the central and the western regions of China. Therefore, while ensuring the economic growth in the central and the western regions, measures must be taken to speed up the adjustment of industrial structure and optimize the structure to improve carbon emission performance. The policy maker should also pay attention to the derivative changes in energy structure when altering the mode of development. These proposals also apply to some other developing countries, such as the BRICS countries (Brazil, Russia, India, and China).

\subsection{Rational Utilization of Foreign Fund}

The central and the western regions of China should continue to uphold the principles of "active but cautious developing of foreign trade and introducing of foreign capital". For all developing countries, scientific evaluation systems should be established, and intensive monitoring should be conducted on the environmental effects of foreign investment. They should prevent resources waste and environmental destruction when introducing advanced production technologies and equipment to take full advantage of foreign investment and foreign capital in order to improve carbon technology and carbon emission efficiency.

\subsection{Improvement of Energy Efficiency}

The government should actively promote the technical exchanges and the cooperation between the eastern and the western regions, give support to the flowing of capital, talents, and advanced technology from the eastern region to the western region, and break the regional barriers that impede energy efficiency improvement and factor mobility to narrow the huge difference in energy efficiency among regions and accelerate the improvement of energy efficiency in backward regions.

\subsection{The Strengthening of Government Intervention}

Currently, the Chinese government subsidizes some of the low-carbon industries but does not levy carbon tax on industries with high carbon emissions. The Carbon Emissions Trading Market is an effective supplement of the fiscal and taxation counter measures. By employing the price modulating and directing mechanism of the market, the government can properly prize the carbon emission right to solve the problems of high carbon emissions and low carbon emission efficiency. In the process 
of industrial transformation, the government should put more emphasis on supervision, guidance, and strict formulation of access criteria. To avoid pollution transferring and carbon leakage in the process of industrial transferring, the rational resources development and environmental protection must be taken into full consideration. Government plays an indispensable role in the countries of transition, but how to handle the relationship between the government and the market in the transition process is still a worldwide problem.

Author Contributions: Data collection and analyzing data, writing—original draft preparation and review, S.W.; writing-review and editing, J.D.; review of draft manuscript, H.W. and L.Z.

Funding: The work is supported by the Major Project of the National Social Sciences Foundation of China (Grant NO. 1282D070); the Key Project of the National Social Sciences Foundation of China (No. 11AZD028); Projects of the Social Science Foundation of Shaanxi Province (No. 13D193); Projects of the Social Science Foundation of Xi'an (No. 19J129).

Acknowledgments: The authors would like to thank the editors and anonymous reviewers for their constructive comments and valuable suggestions on this article.

Conflicts of Interest: The authors declare no conflict of interest.

\section{References}

1. Herendeen, R.; Tanaka, J. Energy cost of living. Energy 1976, 1, 165-178. [CrossRef]

2. Kok, R.; Benders, R.M.J.; Moll, H.C. Measuring the environmental load of household consumption using some methods based on input-output energy analysis: A comparison of methods and a discussion of results. Energy Policy 2006, 34, 2744-2761. [CrossRef]

3. Lenzen, M. Primary energy and greenhouse gases embodied in Australian final consumption: An input-output analysis. Energy Policy 1998, 26, 495-506. [CrossRef]

4. Cho, S.H.; Chae, C.U. A Study on Life Cycle $\mathrm{CO}_{2}$ Emissions of Low-Carbon Building in South Korea. Sustainability 2016, 8, 579. [CrossRef]

5. Zhang, L.x.; Hu, Q.H.; Zahng, F. Input-output modeling for urban energy consumption in Beijing: Dynamics and comparison. PLoS ONE 2014, 9, e89850. [CrossRef]

6. Li, F.; Song, Z.; Liu, W. China's energy consumption under the global economic crisis: Decomposition and sectoral analysis. Energy Policy 2014, 64, 193-202. [CrossRef]

7. Xi, W.; Hua, C.; Florig, H.K. Energy-saving implications from supply chain improvement: An exploratory study on China's consumer goods retail system. Energy Policy 2016, 95, 411-420.

8. Supasa, T.; Hsiau, S.S.; Lin, S.M.; Wongsapai, W.; Chang, K.F.; Wu, J.C. Sustainable energy and $\mathrm{CO}_{2}$ reduction policy in Thailand: An input-output approach from production- and consumption-based perspectives. Energy Sustain. Dev. 2017, 41,36-48. [CrossRef]

9. Rui, X.; Hu, G.; Zhang, Y.; Yu, L. Provincial transfers of enabled carbon emissions in China: A supply-side perspective. Energy Policy 2017, 107, 688-697.

10. Ju, Y.Y.; Kiyoshi, F. Modeling the cost transmission mechanism of the emission trading scheme in China. Appl. Energy 2019, 236, 172-182. [CrossRef]

11. Schimel. $\mathrm{CO}_{2}$ and Carbon Cycle in Climate Change 1994: Radioactive Forcing of Climate Change (IPCC); Cambridge University Press: Cambridge, UK, 1995.

12. Kasperowicz, R. Economic growth and $\mathrm{CO}_{2}$ emissions: The ECM analysis. J. Int. Stud. 2015, 8, 91-98.

13. Zimmermannová, J.; Čermák, P.; Novák, P. Ex-post analysis of the EU emission trading in year 2013 in the Czech Republic. Econ. Sociol. 2015, 8, 172-189. [CrossRef] [PubMed]

14. Stavytskyy, A.; Kharlamova, G.; Giedraitis, V.; Šumskis, V. Estimating the interrelation between energy security and macroeconomic factors in European countries. J. Int. Stud. 2018, 11, 217-238. [CrossRef] [PubMed]

15. Straczewska, I. System of environmental management as an element of bioeconomy development. J. Int. Stud. 2013, 6, 155-163. [CrossRef] 
16. Sun, J.W. The decrease of CO emission intensity is decarbonization at national and global levels. Energy Policy 2005, 33, 975-978. [CrossRef]

17. Charnes, A.; Cooper, W.W. A Brief History of a Long Collaboration in Developing Industrial Uses of Linear Programming. Oper. Res. 2002, 50, 35-41.

18. Hu, J.L.; Wang, S.C. Total-factor energy efficiency of regions in China. Energy Policy 2006, 34, 3206-3217. [CrossRef]

19. Forsund, F.R.; Kittelsen, S.A. Productivity development of Norwegian electricity distribution utilities. Resour. Energy Econ. 1998, 20, 207-224. [CrossRef]

20. Wang, M.; Yu, L.; Liu, Y.; Yang, S.X. Assessing Multiple Pathways for Achieving China's National Emissions Reduction Target. Sustainability 2018, 10, 2196. [CrossRef]

21. Hayami, Y. Sources of agricultural productivity gap among selected countries. Am. J. Agric. Econ. 1969, 51, 564-575. [CrossRef]

22. Battese, G.E.; Rao, D.P. Technology gap, efficiency, and a stochastic metafrontier function. Int. J. Bus. Econ. 2002, 1, 87-93.

23. O'donnell, C.J.; Rao, D.P.; Battese, G.E. Metafrontier frameworks for the study of firm-level efficiencies and technology ratios. Empir. Econ. 2008, 34, 231-255. [CrossRef]

24. Wu, L.; Kaneko, S.; Matsuoka, S. Dynamics of energy-related $\mathrm{CO}_{2}$ emissions in China during 1980 to 2002 : The relative importance of energy supply-side and demand-side effects. Energy Policy 2006, 34, 3549-3572. [CrossRef]

25. Galeotti, M.; Lanza, A. Desperately seeking environmental Kuznets. Environ. Model. Softw. 2005, 20, $1379-1388$. [CrossRef]

26. Su, B.; Ang, B.W.; Li, Y. Input-output and structural decomposition analysis of Singapore's carbon emissions. Energy Policy 2017, 105, 484-492. [CrossRef]

27. Morioka, R.; Nansai, K.; Tsuda, K. Role of linkage structures in supply chain for managing greenhouse gas emissions. J. Econ. Struct. 2018, 7, 7-26. [CrossRef]

28. Hu, Y.; Yin, Z.; Ma, J.; Du, W.C.; Liu, D.H.; Sun, L.X. Determinants of GHG emissions for a municipal economy: Structural decomposition analysis of Chongqing. Appl. Energy 2017, 196, 162-169. [CrossRef]

29. Wang, H.; Ang, B.W.; Su, B. A Multi-region Structural Decomposition Analysis of Global $\mathrm{CO}_{2}$ Emission Intensity. Ecol. Econ. 2017, 142, 163-176. [CrossRef]

30. Zhang, Y.J.; Bian, X.J.; Tan, W.; Song, J. The indirect energy consumption and $\mathrm{CO}_{2}$ emission caused by household consumption in China: An analysis based on the input-output method. J. Clean. Prod. 2017, 163, 69-83. [CrossRef]

31. Shao, L.; Li, Y.; Feng, K.; Meng, J. Carbon emission imbalances and the structural paths of Chinese regions. Appl. Energy 2018, 215, 396-404. [CrossRef]

32. Seiford, L.M.; Zhu, J. Modeling undesirable factors in efficiency evaluation. Eur. J. Oper. Res. 2002, 142, 16-20. [CrossRef]

33. Dong, F.; Li, X.; Long, R.; Liu, X. Regional carbon emission performance in China according to a stochastic frontier model. Renew. Sustain. Energy Rev. 2013, 28, 525-530. [CrossRef]

34. Huang, B.; Meng, L. Convergence of per capita carbon dioxide emissions in urban China: A spatio-temporal perspective. Appl. Geogr. 2013, 40, 21-29. [CrossRef]

35. Wang, J.; Zhang, K. Convergence of carbon dioxide emissions in different sectors in China. Energy 2014, 65, 605-611. [CrossRef]

36. Wang, Y.; Zhang, P.; Huang, D.; Cai, C. Convergence behavior of carbon dioxide emissions in China. Econ. Model. 2014, 43, 75-80. [CrossRef]

37. Zhang, M.; Mu, H.; Ning, Y.; Song, Y. Decomposition of energy-related $\mathrm{CO}_{2}$ emission over 1991-2006 in China. Ecol. Econ. 2009, 68, 2122-2128. [CrossRef]

38. Luukkanen, J.; Kaivo-Oja, J. ASEAN tigers and sustainability of energy use-decomposition analysis of energy and $\mathrm{CO}_{2}$ efficiency dynamics. Energy Policy 2002, 30, 281-292. [CrossRef]

39. Ang, B.W. Is the energy intensity a less useful indicator than the carbon factor in the study of climate change? Energy Econ. 1999, 32, 194-201. [CrossRef] 
40. Fan, Y.; Liu, L.C.; Wu, G.; Tsai, H.-T.; Wei, Y.-M. Changes in carbon intensity in China: Empirical findings from 1980-2003. Ecol. Econ. 2007, 62, 683-691. [CrossRef]

41. Stern, D.I.; Jotzo, F. How ambitious are China and India's emissions intensity targets. Energy Policy 2010, 38, 6776-6783. [CrossRef]

(C) 2019 by the authors. Licensee MDPI, Basel, Switzerland. This article is an open access article distributed under the terms and conditions of the Creative Commons Attribution (CC BY) license (http://creativecommons.org/licenses/by/4.0/). 